\title{
Microstructure influence on fatigue behaviour of nodular cast iron
}

\author{
P. Čanžar, Z. Tonković* ${ }^{*}$ J. Kodvanj \\ Institute of Applied Mechanics, Faculty of Mechanical Engineering and Naval Architecture, University of Zagreb, I. Lučića 5, 10000 Zagreb, Croatia
}

\section{A R T I C L E I N F O}

\section{Article history:}

Received 28 December 2011

Received in revised form

21 May 2012

Accepted 17 June 2012

Available online 29 June 2012

\section{Keywords:}

Nodular cast iron

Microstructure

Experiment

Cyclic tests

Fatigue

Crack growth

\begin{abstract}
A B S T R A C T
The present paper evaluates the fatigue life of ductile nodular cast iron EN-GJS-400-18LT with four different microstructures. Characterisation of the graphite morphology and the matrix microstructure is performed on 50 samples for every material type. Tensile stress-strain curves, symmetrical and unsymmetrical stress-strain hysteresis loops, cyclic stress-strain curves, crack resistance curves and fatigue life curves of these four microstructures are obtained. Experimental results show that size, shape and distribution of the graphite nodules has no significant influence on cyclic hardening of the material but they play a great role in the crack initiation and propagation process. It is shown that the larger irregularly shaped nodules reduce fracture toughness and fatigue strength. Furthermore, the results demonstrated that pearlitic phase does not strongly affect fatigue life if its proportion does not exceed $10 \%$. The monitoring of crack length during the tests is performed by an optical method developed in the present work.
\end{abstract}

(c) 2012 Elsevier B.V. All rights reserved.

\section{Introduction}

The majority of modern wind turbine components, such as rotor hubs, tubular adapters, main frames and axles, are made of a nodular cast iron. The nodular cast iron grade EN-GJS-400-18-LT, in which graphite spheroids or nodules in a ferritic matrix provide large ductility and fatigue strength, is widely used. Specific shape of the graphite in the ferritic microstructure acts as the crack arrester and lowers the stress intensity in front of the crack, which makes it an appropriate material for such cyclically loaded structures [1-5]. Therefore, in order to prevent catastrophic failures and to prolong the service lifetime of wind turbine structures, it is important to consider the influence of the graphite nodule geometrical features (size, shape and distribution of nodules) on the fatigue crack initiation and propagation at the root of a geometrical discontinuity and local notches. In addition to the form of graphite nodules, the mechanical properties of cast iron are determined by the metal matrix. The ferritic cast iron is normally soft and ductile, while the pearlitic matrix exhibits high strength and hardness and is prone to brittle fracture [6]. A matrix with both ferritic and pearlitic phase with intermediate mechanical properties is often found in practice.

Numerous investigations have been carried out during the past decades to determine influence of microstructure on the mechanical behaviour of the nodular cast iron [7-13]. Researchers at the Technical University, Bergacademy Freiberg, have investigated

\footnotetext{
* Corresponding author. Tel.: +38516168 450; fax: +38516168187.

E-mail address: zdenko.tonkovic@fsb.hr (Z. Tonković).
}

the fracture behaviour of EN-GJS-400-18-LT nodular cast iron with a ferritic matrix and spherical graphite of three different sizes under cyclic and random loading [14-16]. It is found that the increasing graphite particle size leads to higher threshold values $\Delta K_{\mathrm{th}}$, lower $\mathrm{d} a / \mathrm{d} N$ values and higher transition to static fracture $K_{\mathrm{c}}$. Therein, the circular shape factor (CSF) that describes the deviation from the spherical graphite shape had approximately the same value of 0.8 ( $\mathrm{CSF}=1$ for an ideal sphere). In their latest paper [17] the same nodular cast iron with two different graphite spherical sizes is analyzed. Material with approximately 70\% larger nodules and lower density distribution had 30\% smaller shape factor (CSF) in contrast to the finer graphite microstructure. Despite the little difference between results obtained for the coarse and fine graphite microstructures, the authors have concluded that the increase of graphite particle size causes an increase of threshold value and critical stress intensity factor, in the same way as mentioned above. However, the results presented in this paper also show that the graphite shape factor as an indicator of the internal notch effect has strong influence on the fatigue behaviour of the nodular cast iron with a ferritic matrix. Thus, more research is needed for a better understanding of the mechanical behaviour of the nodular cast iron EN-GJS-40018-LT. There are only limited experimental data available on fatigue crack growth behaviour of EN-GJS-400-18-LT and still the effect of the graphite morphology (size, shape and distribution) as well as microstructure phase (ferritic and pearlitic) on fracture toughness and fatigue properties of this material is not well documented.

This paper presents an experimental study of the cyclic deformation and fatigue behaviour of nodular cast iron depending 
on the material microstructure. Four types of cast iron EN-GJS400-18-LT produced by different technologies are considered. In the first part of the experimental investigation, the metallographic analyses are performed and the microstructural parameters are presented. In the second part, the cyclic stress-strain curves of these four microstructures are obtained and the parameters of Ramberg-Osgood expression are given. The main part of this manuscript is the third part where the fatigue crack growth and the fracture toughness tests are performed. Additionally, this section contains description of the new optical method

Table 1

Chemical composition of four types of cast iron EN-GJS-400-18-LT (weight \%).

\begin{tabular}{llllllll}
\hline Material type & $\mathrm{C}$ & $\mathrm{Si}$ & $\mathrm{Mn}$ & $\mathrm{P}$ & $\mathrm{S}$ & $\mathrm{Ni}$ & $\mathrm{Mg}$ \\
\hline 100 & 3.6 & 2.122 & 0.204 & 0.023 & 0.004 & 0.978 & 0.046 \\
200 & 3.6 & 2.044 & 0.112 & 0.023 & 0.003 & 0.619 & 0.037 \\
300 & 3.6 & 1.968 & 0.114 & 0.024 & 0.003 & 0.572 & 0.039 \\
400 & 3.6 & 1.976 & 0.102 & 0.021 & 0.002 & 0.674 & 0.033 \\
\hline
\end{tabular}

a

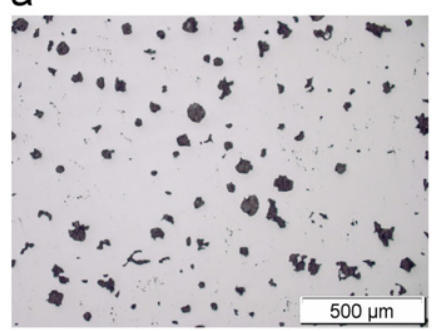

C

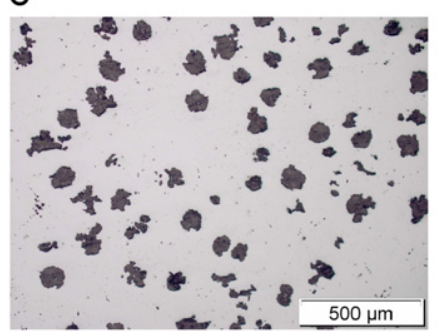

e

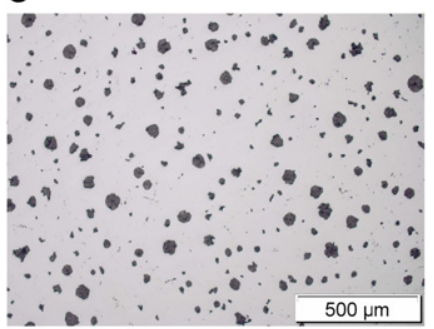

g

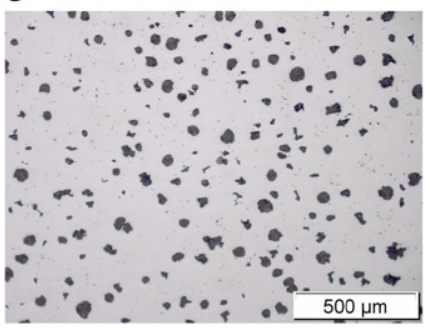

b

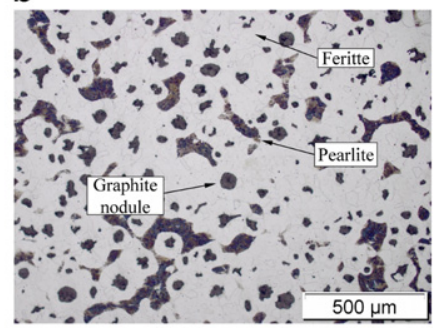

d

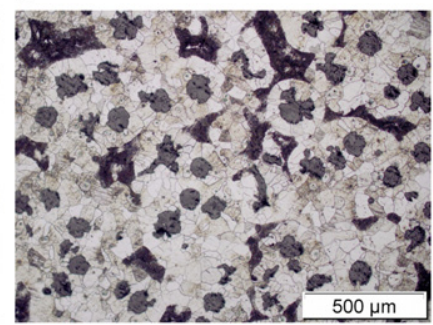

$\mathrm{f}$

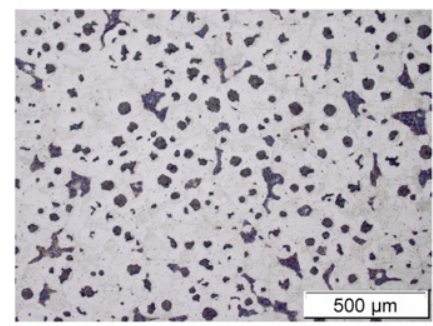

$\mathrm{h}$

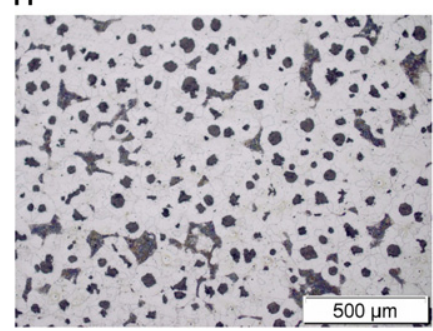

Fig. 1. Metallography of primary (a, c, e, g) and secondary (b, d, f, h) microstructure for: (a) type 100, (b) type 200, (c) type 300 and (d) type 400 of the nodular cast iron. for the determination of the crack tip position developed in the present work. Finally, some concluding remarks are given in the last section.

\section{Materials and specimens}

The investigated materials have been provided by the company MIV Varaždin, Croatia. Different types of cast iron are referred to as type 100 , type 200 , type 300 and type 400 . For producing nodular cast iron, one non-standard technique (type 100 ) and three standard techniques (flotret-type 200, tundish-type 300, and inmould-type 400) are applied. These techniques for the cast iron production are based on adding magnesium to the molten metal. A detailed description of the above-mentioned standard methods can be found in Ref. [6]. Table 1 shows the chemical composition of the test materials. It may be observed that the chemical compositions of investigated materials are similar except that the $\mathrm{Mn}, \mathrm{Ni}$ and $\mathrm{Mg}$ contents are higher in the material type 100 .

The graphite morphology of the casting types which includes the primary (unetched) and secondary (etched) microstructures is shown in Fig. 1. The primary, unetched microstructure is used for measuring the graphite proportion, while the total proportion of ferrite, graphite and pearlite is measured on the secondary, etched microstructure. For deriving the secondary microstructure (Fig. 1b, d, f and h), specimens are fine brushed, polished, and afterwards etched in $5 \%$ solution of nitric acid $\left(\mathrm{HNO}_{3}\right)$ in alcohol.

A large amount of metallographic samples are analyzed but only some results are presented and shown in Table 2. The geometric characteristics of the microstructure shown in Table 2 are obtained from 10 randomly positioned places on each of the five samples for each material type, which altogether gives 50 metallographic samples for every material type. Since there is a rather cumbersome amount of metallographic samples data, they

Table 2

Metallographic characteristics of nodular cast iron.

\begin{tabular}{|c|c|c|c|c|c|c|}
\hline \multirow{2}{*}{$\begin{array}{l}\text { Material } \\
\text { type }\end{array}$} & \multirow[t]{2}{*}{ Sample } & \multicolumn{3}{|c|}{ Graphite nodules } & \multicolumn{2}{|l|}{ Pearlite } \\
\hline & & $\begin{array}{l}\text { Number } \\
\left(\mathrm{mm}^{-2}\right)\end{array}$ & $\begin{array}{l}\text { Average size } \\
\left(\mu \mathrm{m}^{2}\right)\end{array}$ & Circularity & Area $\left(\mu \mathrm{m}^{2}\right)$ & $\%$ \\
\hline \multirow[t]{6}{*}{100} & 102 & 84 & 1200.03 & 0.68 & $124,297.53$ & 12.43 \\
\hline & 103 & 90 & 1098.28 & 0.71 & $84,248.77$ & 8.42 \\
\hline & 104 & 99 & 945.01 & 0.73 & $59,472.86$ & 5.95 \\
\hline & 106 & 56 & 1272.05 & 0.63 & $130,833.31$ & 13.08 \\
\hline & 108 & 92 & 677.80 & 0.72 & $55,650.31$ & 5.57 \\
\hline & Average & 84 & 1038.63 & 0.70 & $90,900.56$ & 9.09 \\
\hline \multirow[t]{6}{*}{200} & 202 & 61 & 1377.37 & 0.57 & $34,255.20$ & 3.43 \\
\hline & 203 & 64 & 1333.10 & 0.59 & $44,733.47$ & 4.47 \\
\hline & 204 & 53 & 1557.95 & 0.56 & $57,822.64$ & 5.78 \\
\hline & 206 & 58 & 1232.22 & 0.60 & $53,407.96$ & 5.34 \\
\hline & 208 & 50 & 1583.36 & 0.56 & $59,407.78$ & 5.94 \\
\hline & Average & 57 & 1416.80 & 0.57 & $49,925.41$ & 4.99 \\
\hline \multirow[t]{7}{*}{300} & 304 & 91 & 651.44 & 0.71 & $77,500.19$ & 7.75 \\
\hline & 305 & 96 & 708.28 & 0.72 & $85,870.40$ & 8.59 \\
\hline & 307 & 86 & 911.64 & 0.69 & $81,414.01$ & 8.14 \\
\hline & 308 & 90 & 656.59 & 0.72 & $55,418.11$ & 5.54 \\
\hline & 309 & 82 & 864.65 & 0.69 & $64,643.53$ & 6.46 \\
\hline & 310 & 91 & 686.70 & 0.71 & $93,424.35$ & 9.34 \\
\hline & Average & 89 & 746.55 & 0.71 & $76,378.43$ & 7.64 \\
\hline \multirow[t]{7}{*}{400} & 402 & 70 & 998.62 & 0.64 & $81,675.86$ & 8.17 \\
\hline & 403 & 97 & 712.00 & 0.71 & $39,472.13$ & 3.95 \\
\hline & 404 & 72 & 982.48 & 0.65 & $86,852.35$ & 8.69 \\
\hline & 410 & 70 & 1003.09 & 0.64 & $90,597.94$ & 9.06 \\
\hline & 411 & 105 & 541.80 & 0.69 & $52,118.42$ & 5.21 \\
\hline & 412 & 77 & 784.55 & 0.62 & $67,641.15$ & 6.76 \\
\hline & Average & 81 & 837.09 & 0.66 & $69,726.31$ & 6.97 \\
\hline
\end{tabular}


are not given in this paper for the conciseness reason. Some deviation from the mean values always exists but in overall, values fit well in the given averages from Table 2 . The first microstructural parameter in Table 2, nodule count, is expressed as the average number of graphite nodules per $\mathrm{mm}^{2}$. According to the definition by Russ (1995), the circularity or the circular shape factor (CSF) is given as

$\mathrm{CSF}=\frac{4 \cdot \pi \cdot A}{P^{2}}$,

where $A$ represents the area and $P$ is the perimeter or circumference of the graphite nodule. As mentioned above, circularity

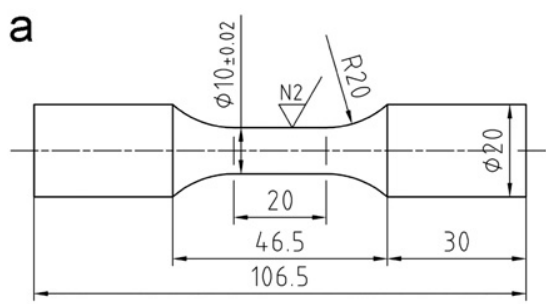

b
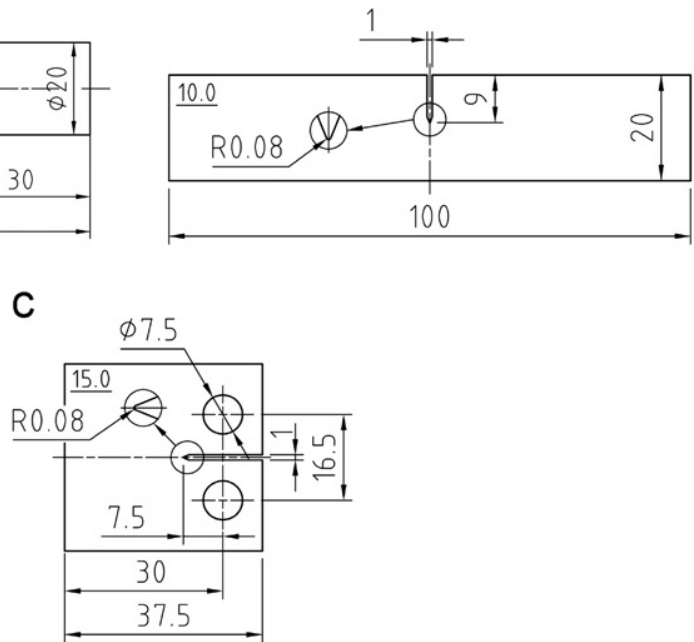

Fig. 2. Shape and dimensions of specimens. (a) Cylindrical specimen for cyclic testing; (b) SEB specimen for three-point bending testing and (c) CT specimen.

a

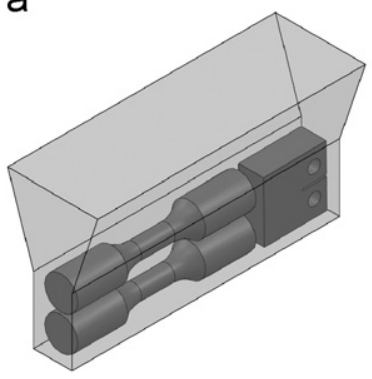

b

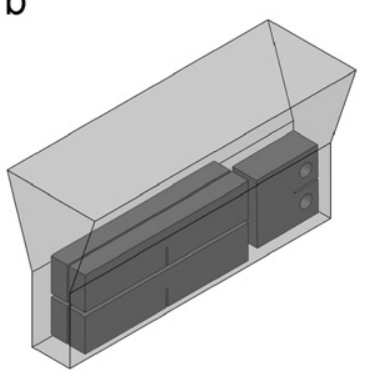

C

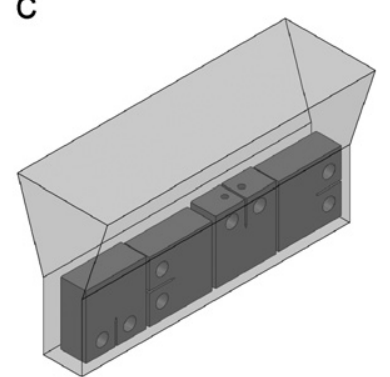

Fig. 3. Specimens orientation in Y-block casting: (a) cylindrical; (b) SEB and (c) CT specimen.

a

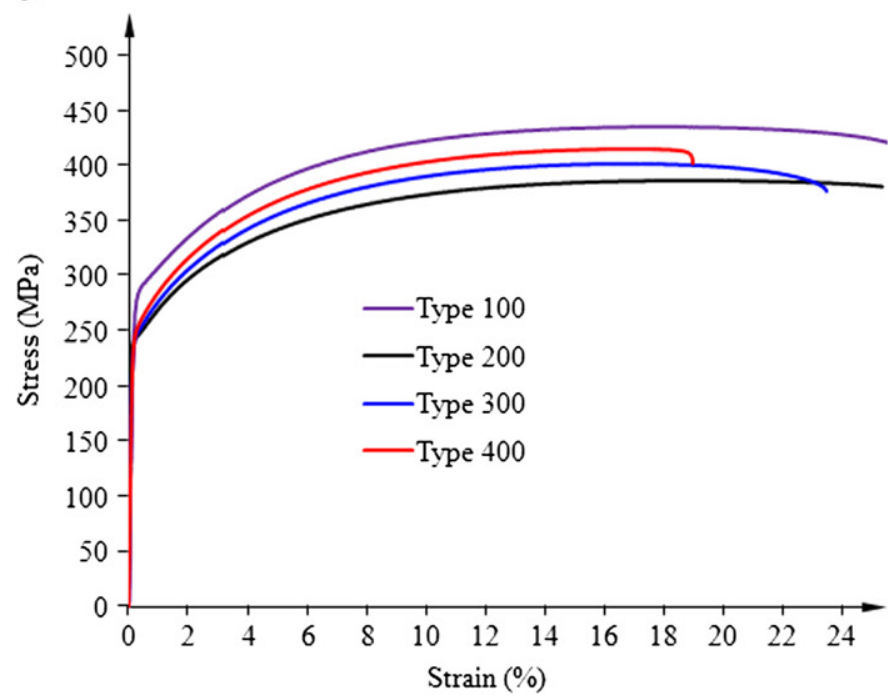

b

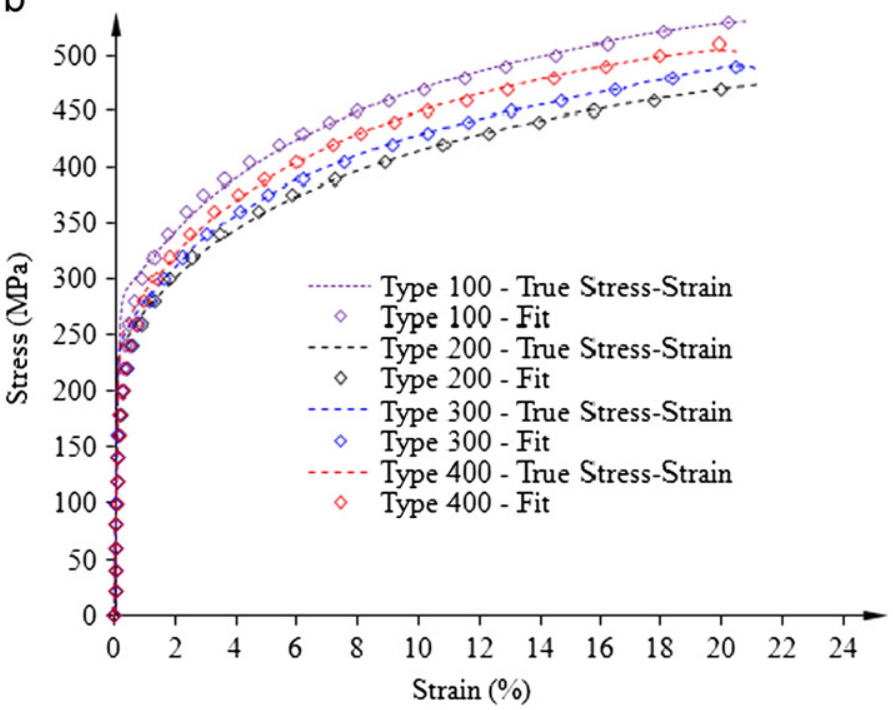

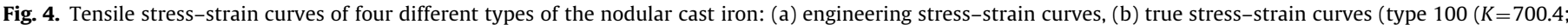
$n=0.1726)$, type $200(K=630.4 ; n=0.1809)$, type $300(K=666.7 ; n=0.1869)$ and type $400(K=691,3 ; n=0.1868)$. 
varies between 0 and 1 , the maximum value corresponding to perfect geometric shapes and the minimum corresponding to irregular shapes. As it can be seen from Fig. 1 and Table 2, the differences between the materials are in the graphite nodule geometrical features, count number, size and ferrite to pearlite volume proportion. The volume proportion of pearlite of material types $100,200,300$ and 400 are $9.09 \%, 4.99 \%, 7.64 \%$ and $6.97 \%$, respectively. Accordingly, all four types of materials have a predominantly ferritic matrix (approximately 90\% ferrite and maximum of $10 \%$ of pearlitic phase). Moreover, material type 200 produced by the flotret process has significantly larger nodules with low density distribution than the other three types of nodular cast iron. Besides, material type 200 has graphite nodules with the lowest circularity (irregularly shaped nodules) and lower content of pearlitic grain. On the other hand, material types 300 and 400 produced by the tundish and inmould process have smaller ferrite grains and smaller nodules, more spherical

Table 3

Mechanical properties of nodular cast.

\begin{tabular}{lllllll}
\hline Material type & $\sigma_{0.2}(\mathrm{MPa})$ & $\sigma_{\mathrm{u}}(\mathrm{MPa})$ & $E(\mathrm{GPa})$ & $K(\mathrm{MPa})$ & $n$ & $J_{0.2}\left(\mathrm{~kJ} / \mathrm{m}^{2}\right)$ \\
\hline 100 & 286.4 & 435.1 & 163.4 & 700.4 & 0.1726 & 81.9 \\
200 & 244.0 & 385.8 & 180.0 & 630.4 & 0.1809 & 74.0 \\
300 & 250.0 & 402.0 & 215.9 & 666.7 & 0.1869 & 86.0 \\
400 & 255.8 & 417.2 & 199,9 & 691.3 & 0.1868 & 84.5 \\
\hline
\end{tabular}

a

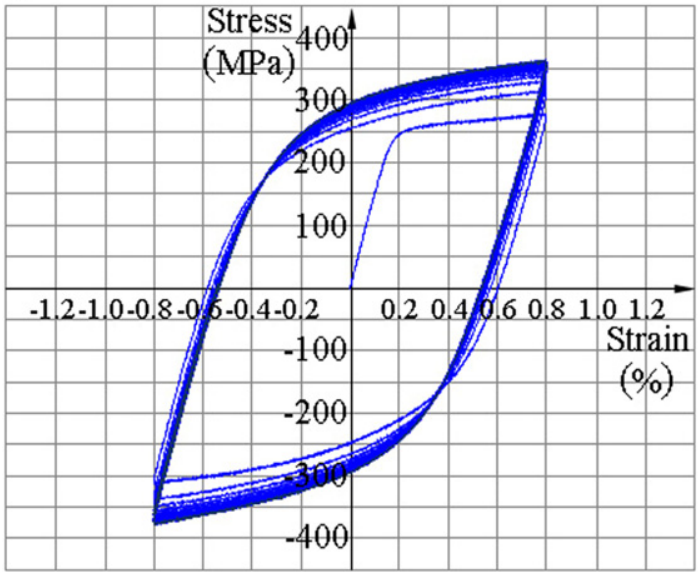

C

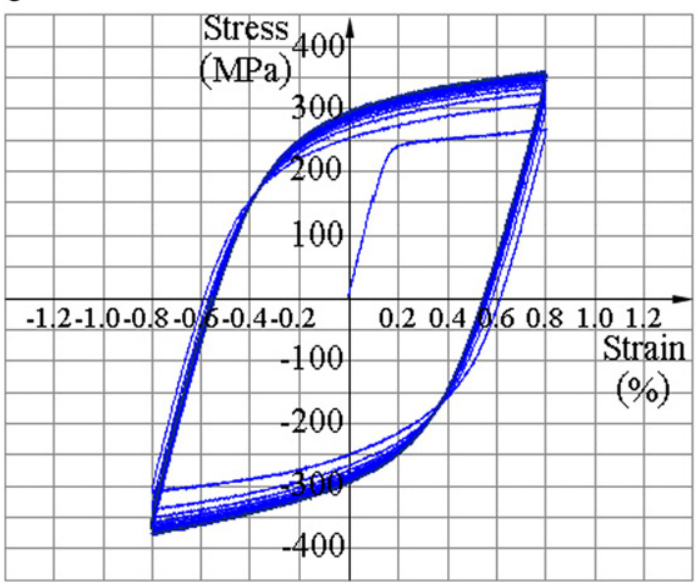

and regular in shape than those in the material type 200. Furthermore, material type 100 has the highest content of pearlite. All these facts have a strong influence on the fatigue behaviour of the nodular cast iron.

Fig. 2 illustrates the schematic shape and geometry of specimens required for the monotonic, cyclic and fatigue tests. It consists of a polished cylindrical specimen used for cyclic testing (Fig. 2a), single edge bending (SEB) specimen (Fig. 2b) and compact tension (CT) specimen (Fig. 2c) according to the standards ASTM E606, ASTM E1820 and ASTM E647. Specimens are cut and machined from the Y-block castings of dimensions $160 \mathrm{~mm} \times 40 \mathrm{~mm} \times 23 \mathrm{~mm}$. Fig. 3 shows specimen orientation in Y-block casting. Monotonic tensile, uniaxial cyclic and fatigue tests are carried out at room temperature on a Walter Bai servohydraulic testing machine with a load capacity of $\pm 50 \mathrm{kN}$.

\section{Uniaxial monotonic tensile and cycle tests}

Monotonic tensile as well as cyclic tests are carried out on the smooth cylindrical specimens. Specimens used for tensile test are manufactured according to DIN 50125, while the specimens used for strain controlled fatigue testing are manufactured according to ASTM E606. In this section, a short description of test procedure is given, and some selected test results are presented.

Engineering and true stress-strain curves for all four types of material are shown in Fig. 4. During the test a video extensometer is used to measure reduction of a cross-section allowing b

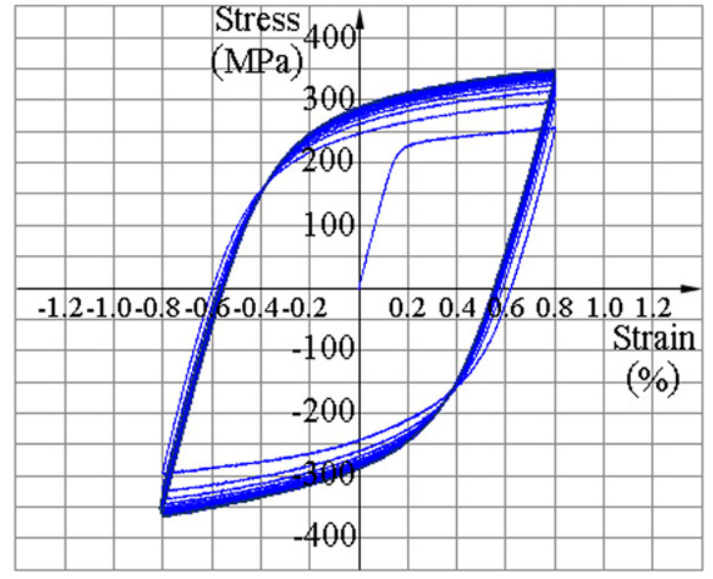

d

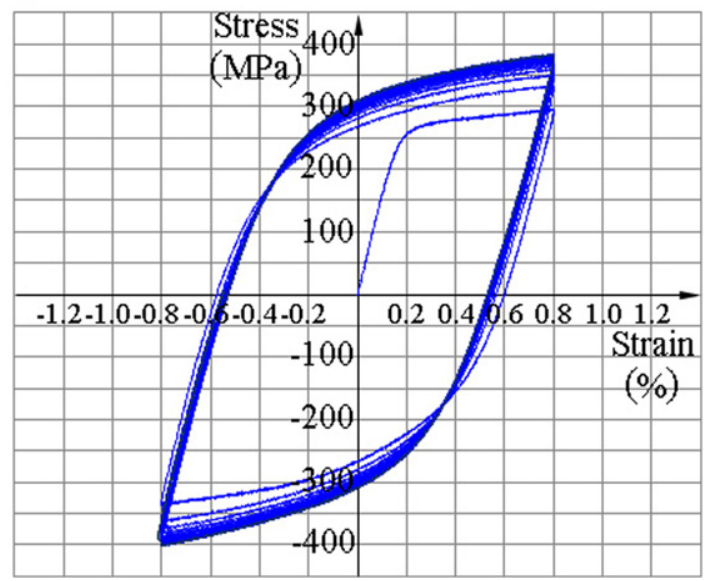

Fig. 5. Symmetrical stress-strain hysteresis loops for: (a) type 100; (b) type 200; (c) type 300 and (d) type 400 of the nodular cast iron. 
calculation of a true stress and Poisson's ratio. True stress-strain curves are analytically described by the well-known RambergOsgood model in the following form:

$\varepsilon=\frac{\sigma}{E}+\left(\frac{\sigma}{K}\right)^{1 / n}$

where $E$ is Young's modulus, while $n$ and $K$ represent the parameters used for fitting the experimentally obtained curves. These parameters are shown in Fig. 4 for all four types of nodular cast iron. Obtained mechanical properties are listed in Table 3. As shown in Fig. 4 and Table 3, material type 100, with the highest content of pearlite, has higher yield and ultimate tensile strength than other three types of materials. Material type 200, with the smallest pearlite fraction, has the weakest mechanical properties. Other two types of material have similar properties which are between material types 100 and 200 .

The series of the uniaxial strain controlled cyclic loading experiments with several combinations of constant load amplitudes are performed on all four material types $[18,19]$. The tests are carried out on the smooth cylindrical specimens (Fig. 2a). The shortest specimen which standard still allows is used to avoid buckling effect during compression part of testing. The strain is controlled with an extensometer of a gauge length of $10 \mathrm{~mm}$. Tests are carried out under fully reversed strain control at constant strain rate of $10^{-3} \mathrm{~s}^{-1}$. Different strain amplitude $(\Delta \varepsilon / 2)$ is applied from the $0.2 \%$ up to the $1.2 \%$ with the increment of $0.2 \%$. In each test 40 stress-strain hysteresis loops are obtained which is more than enough to achieve a stabilised hysteresis curve. Stabilised material behaviour is exhibited after approximately 15 cycles. The representative symmetrical tests $(\Delta \varepsilon / 2= \pm 0.8 \%)$ for each type of nodular cast iron are presented in Fig. 5 . In these tests mean strain is always equal to zero.

Representative cyclic unsymmetrical tests are presented in Fig. 6. In both the tests significant cyclic hardening is observed. Furthermore, comparing corresponding hysteresis loops for the symmetrical and unsymmetrical tests, it can be concluded that mean strain has no significant effect on the cyclic hardening behaviour of the investigated materials. The presented results represent the basis for determination of material parameters of a cyclic plasticity constitutive model like that recently developed by Tonković and Sorić [20-22] and damage criterions based on the stabilised accumulated inelastic hysteresis strain energy [22].

Cyclic elastoplastic behaviour of all four types of nodular cast iron in major part depends on ferritic matrix microstructure which provides large ductility of that material. Since all four types of material have similar share of ferritic grain, expressed in Table 2, differences between aforementioned types of nodular cast iron exist, but they are not so significant. All the four types of material have a similar hardening rate and the major difference between them is in achieving maximum stress in first and all subsequent half-cycles as well as in achieving first yielding point. Considering symmetrical cyclic tests, and as one can assume, the material type 200 has the smallest aforementioned values, while the material type 400 has the largest values. Material types 100 and 300 have similar values of peak half-cycle stresses and first yielding points. Considering unsymmetrical cyclic tests, material types 100 and 400 have similar and largest aforementioned values, while material type 200 has the smallest values. Type 300 shows somewhat better results that the material type 200 . Considering these types of cyclic tests one can conclude in general that the material type 200 has the worst characteristics, while the material type 400 has the best characteristics and most regular behaviour.

The hysteresis behaviour obtained in symmetrical multiple step tests is presented in Fig. 7. Therein, the strain amplitude is increased in steps of $0.2 \%$, while keeping the mean strain equal to a

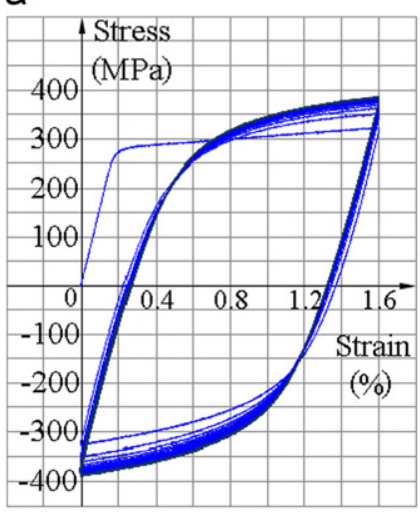

C

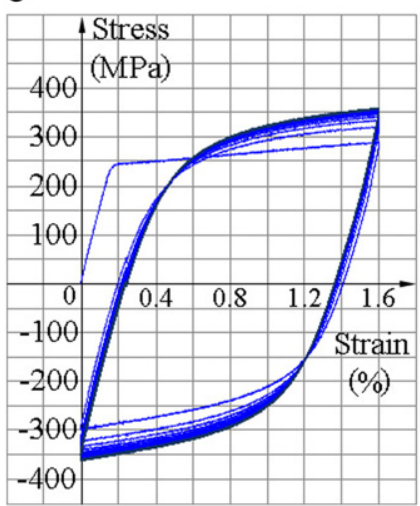

b

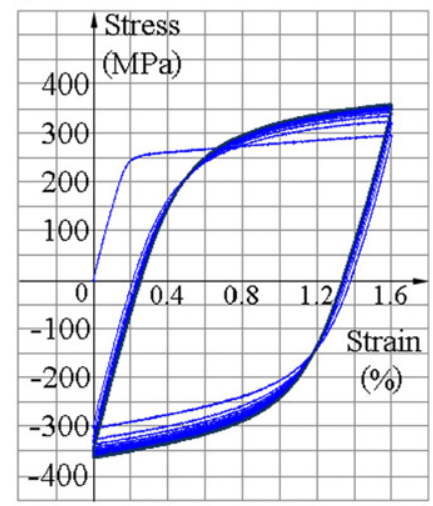

d

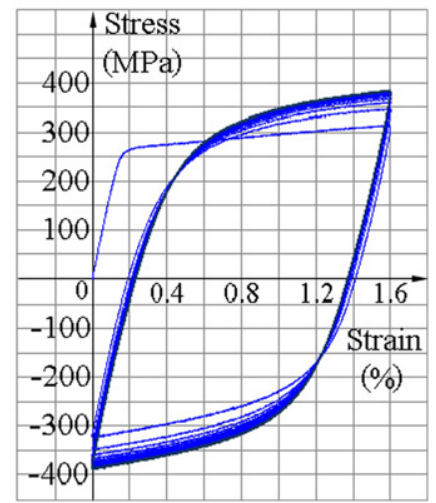

Fig. 6. Unsymmetrical stress-strain hysteresis loops for: (a) type 100; (b) type 200; (c) type 300 and (d) type 400 of the nodular cast iron.

zero. The number of cycles at each step was 15 and the maximum strain amplitude was equal to $\pm 1.2 \%$. The cyclic stress - strain curve which is especially important in studies on low-cycle fatigue and crack propagation is determined by connecting the tips of the stabilised hysteresis loops obtained from specimens tested at different strain levels. The tips of the hysteresis loops are obtained with sufficient accuracy by recording a large number of experimental points. The least squares technique is used to determine the material properties constants, $n^{\prime}$ and $K^{\prime}$, which describe the Ramberg-Osgood expression for the cyclic stress strain curve

$\varepsilon=\frac{\sigma}{E}+\left(\frac{\sigma}{K^{\prime}}\right)^{1 / n^{\prime}}$

Curves with the derived material constants are shown in Fig. 7.

Mean value of parameter $K^{\prime}$ is 898.3 with standard deviation of 80.4 , while $n^{\prime}$ has mean value of 0.17 , with standard deviation of 0.009. It may be noted that the differences between the material parameters are not so significant. Consequently, the size and distribution of graphite nodules have not got major influence on the material cyclic hardening. A comparison of cyclic stress-strain curves for all material types with those available in the literature [23] is shown in Fig. 8. A significant difference between curves shape obtained in the present work and the corresponding curve obtained by Eufinger et al. [23] can be observed. However, an explanation for these differences cannot be given here since detailed data on uniaxial cycle tests and metallographic characteristics (nodularity, nodule circularity, graphite content and pearlite content) of considered nodular cast irons are not provided in Ref. [23]. 
a

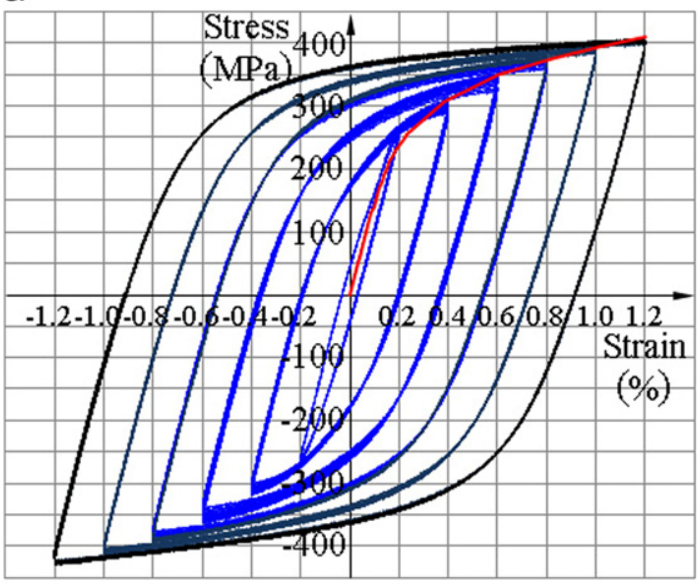

C

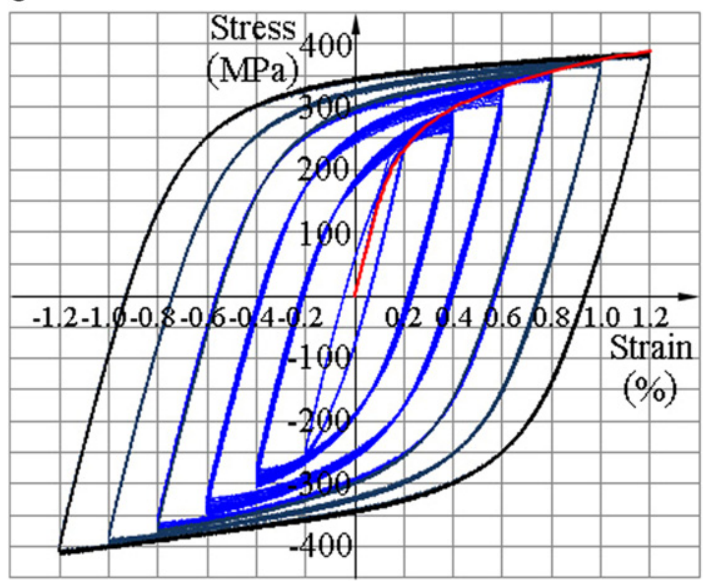

b

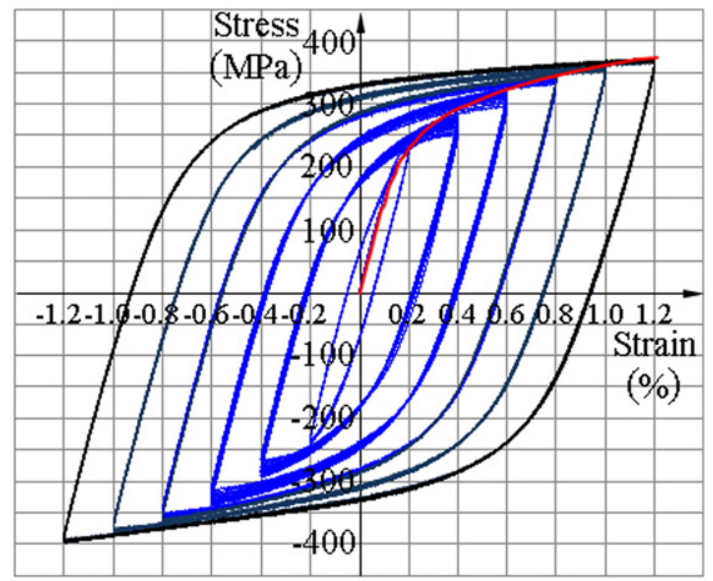

d

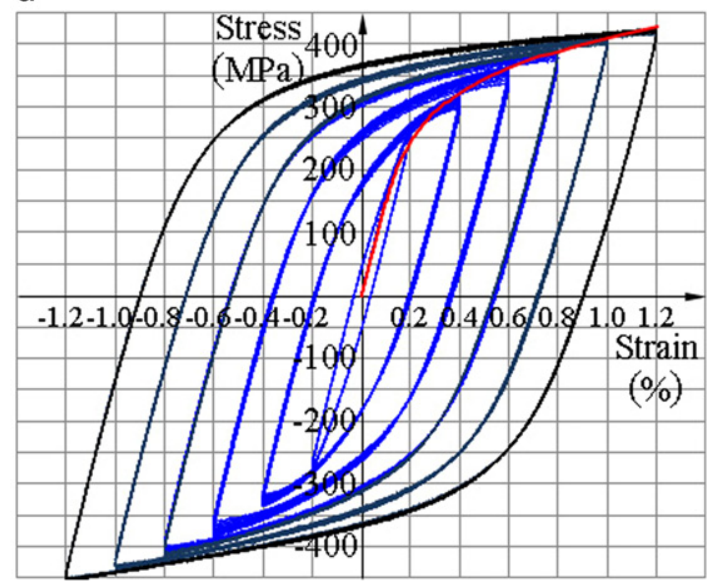

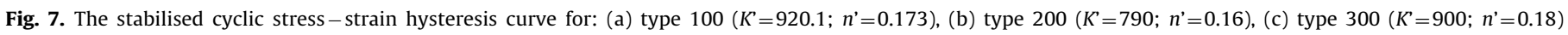
and (d) type $400\left(K^{\prime}=983 ; n^{\prime}=0.178\right)$ of the nodular cast iron.

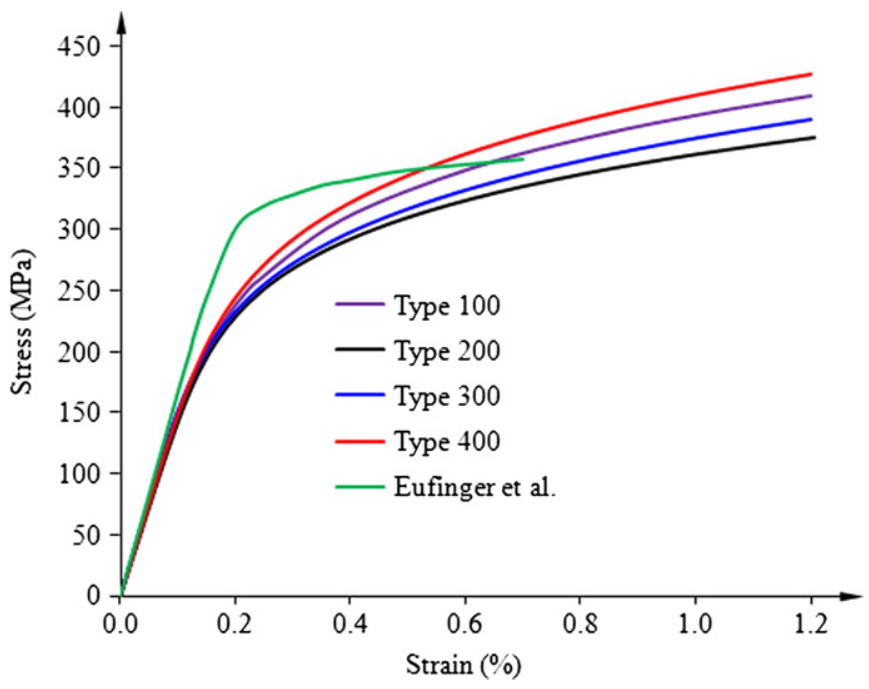

Fig. 8. Cyclic stress-strain curves for all material types.

Differences between materials curves that are subjects of this paper are most noticeably if comparing the maximum achieved stress for the same value of deformation. Accordingly, the largest value is accomplished by material type 400 , then 100,300 , and 200 , counting from largest to smallest value.

\section{Fatigue crack growth tests}

Second part of this research is concerned with the investigation of the crack initiation and propagation under cyclic loading conditions. Region investigated was low cycle fatigue (LCF) expanding to the transient region between LCF and high cycle fatigue (HCF) $\left(10^{4}-10^{5}\right.$ cycles). The tests are performed on the CT specimens (Fig. 2c). Special requirements prescribed by the before mentioned standards and regarding specimen sizing and notch machining is accomplished through careful examination of all specimen under light microscope. Tests are carried out without interrupting the testing procedure after crack initiation (a crack of technical size $a \approx 1 \mathrm{~mm}$ ), because the specimens were never overloaded above the prescribed maximum value specified by the standard ASTM E1820 [24], so consequently there was no significant plasticity introduced. After the process of crack initiation some specimens are fine brushed, polished and etched in order to make visible the graphite nodules in the vicinity of the crack. Fig. 9 shows crack in the vicinity of the specimen's notch with the exposed nodular cast iron microstructure. Since the crack tip is hardly visible and since it can be easily misplaced with the grain boundary under smaller magnifications, cracked specimen is mounted in a special device and loaded with same maximum force (displacement) as in the real testing procedure allowing the crack to open slightly and to capture the crack in the nodular cast iron microstructure. As can be seen, the direction of crack growth is towards the graphite nodule which acts as 


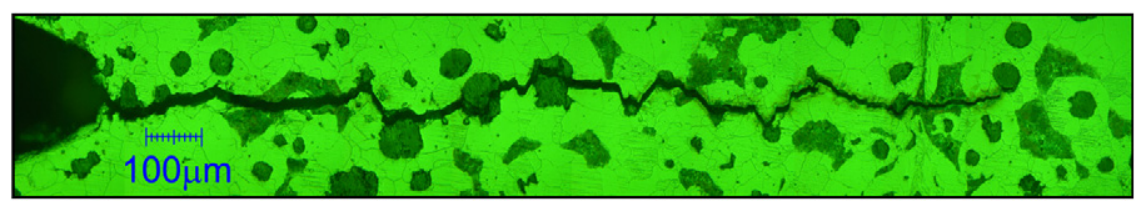

Fig. 9. Crack exposed in microstructure.

a

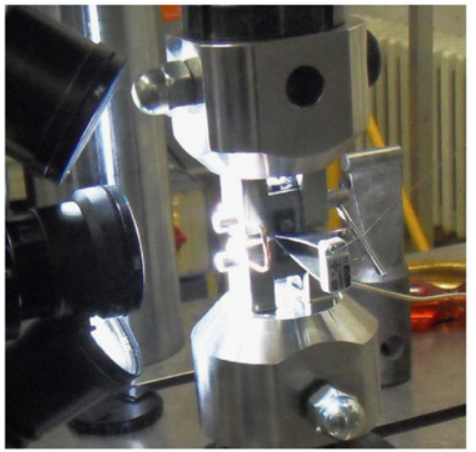

b

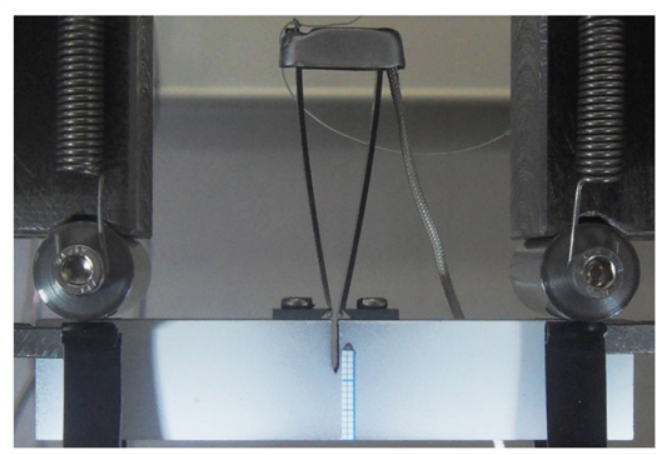

Fig. 10. Specimen and testing configuration for: (a) CT and (b) SENB specimen.
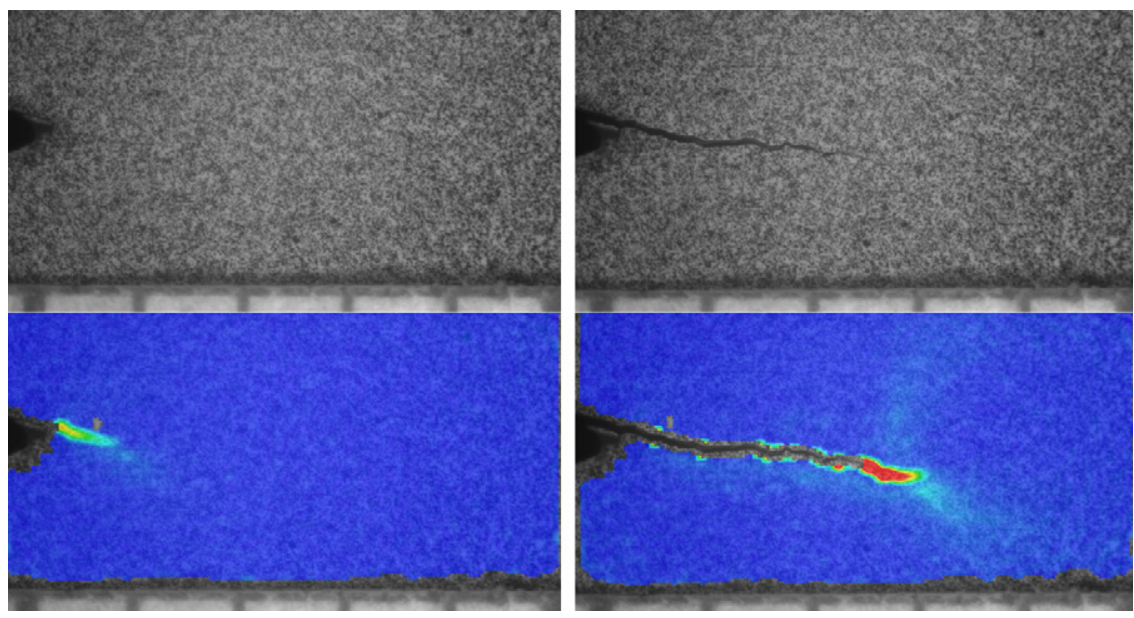

Fig. 11. Crack tip determination using Aramis optical system.

barriers to the crack propagation. As it is described in [25], the fatigue cracks propagate in a zig-zag manner in the ferrite matrix but linearly in the pearlite matrix, because the difference in crack sensitivity depends on the matrix strength and also because the ferrite grain boundary prevents crack propagation. In addition, the fatigue cracks always start at the interface between the graphite nodule and surrounding ferrite matrix, while graphite nodules remain generally unbroken [26].

After crack initiation, specimens are submitted to constant amplitude loading defined by a maximum load of $12 \mathrm{kN}$ and load ratio $R$. Three different loading regimes $(R=0.1, R=0.3$ and $R=0.5$ ) for all material types are performed. The tests are carried out at a frequency of $10 \mathrm{~Hz}$. During the test, crack propagation length is measured by an optical measuring system Aramis [27] on the lateral surface of the specimen. Since the testing is long lasting, there was no reason for measuring every cycle and every small displacement of the specimen. In contrary, every 100th cycle is recorded, and captured at the moment of maximum load, which is imposed by the testing machine, employing $196 \mathrm{kHz}$ sampling. Due to very fast measurement, shutter time was correspondingly small, and consequently lightening of the object has to be significant. Lighting is obtained through the usage of led lamps, since they do not emit a large amount of heat on the nearby specimen and camera objective. CT and SEB specimen testing in the frame of crack measurement and fracture toughness assessment is shown in Fig. 10. As said before for the sake of optical crack measurement and consequently a small measurement volume, a significant amount of lightning upon the object is needed. In Fig. 10a, one can see such lightened CT specimen, as well in Fig. 10b SEB specimen prepared with fine raster (fineground) and special springs for keeping the specimen in the focus of the camera. Besides of measuring crack propagation i.e. the crack size, crack mouth opening displacement (CMOD) is also measured using special extensometers (Fig. 10a).

The field of view of the optical system was $8 \mathrm{~mm} \times 6 \mathrm{~mm}$ while the CCD chip at the camera has 2048 pixels in the direction of the crack length which leads to resolution of $4 \mu \mathrm{m}$ per pixel. The main problem was to find very thin crack tip on black and white surface. In order to improve the resolution and to facilitate crack tip determination, Aramis software for digital image correlation is used (Fig. 11) [27,28]. Now determination of the crack tip is reduced to find user defined deformation in the result file and also the resolution is raised to subpixel level. This technique is completely automated as a real-time process with the scripts 
written in the Python language. This is, to the best of the authors' knowledge, one of the first studies (if not the first) carried out to determine crack tip position during the fatigue test by using the optical measurement system Aramis [27].

Using a newly developed technique for crack tip identification and measurement of crack length, one can develop a dependence diagrams between the crack length $a$ and the number of cycles $N$. Such diagrams, regarding different load ratios $(R=0.1, R=0.3$ and $R=0.5$ ) are shown in Fig. 12 for all four types of nodular cast iron. As may be seen from the Fig. 12 , an increase in the $R$-ratio increases the number of cycles to initiate a fatigue crack as well as the total number of cycles till the final fracture of the specimen. For the most rigorous load ratio $R=0.1$, there is the most pronounced difference in material types regarding crack propagation. Specifically, material type 200, produced by the flotret process, shows the least crack resistance which will be shown later in this paper. On contrary, material type 400 produced by the inmould technique, lasts approximately 2.5 times longer, till the final specimen fracture. Other two types of material show intermediate behaviour. Decreasing the loading amplitude, i.e. raising the $R$ ratio, Fig. $12 \mathrm{~b}$ and c reduces the difference between specimen's life regarding various types of material, except for the type 200 material. The results show that the materials with a large number of smaller as well as with more regularly shaped graphite nodules and small ferrite grains (material types 300 and 400) have larger resistance to initiation and crack propagation resulting in higher fatigue life. A larger number of more regular and smaller nodules contributes more to higher fatigue resistance than a small number of large irregularly shaped graphite nodules that act as an internal notch in the ferritic matrix (material type 200). This agrees with Shiramine et al. [29] conclusions on the influence of graphite nodule size on the impact properties of spheroidal graphite cast iron. The results also show that pearlitic brittle phase, with the proportion of less than $10 \%$, is not so influential on fatigue resistance. These facts confirm that size, shape and distribution of graphite nodules, as well as microstructure phase (ferritic and pearlitic) have a major influence on specimen's life, i.e. crack initiation and propagation.

From the curves presented in Fig. 12, one can develop a fatigue crack growth rate diagrams for all four types of nodular cast iron. Relationships between crack growth rate $\mathrm{d} a / \mathrm{d} N$ and stress intensity factor range $\Delta K$ as a function of $R$ ratios are shown in Fig. 13 for all four types of material. It can be seen that the threshold stress intensity factor range, $\Delta K_{\mathrm{th}}$, decreases with increasing the $R$ ratio. These experimental results are approximated using the NASGRO equation taking into account all three regions of the fatigue crack growth curve and the dependency of the stress ratio

$\frac{\mathrm{d} a}{\mathrm{~d} N}=C(\Delta K)^{m}\left[\frac{1-\left(\Delta K_{\mathrm{th}} / \Delta K\right)^{n_{1}}}{1-\left(\Delta K / K_{\mathrm{Ic}}\right)^{n_{2}}}\right]$,

where $C, m, n_{1}$ and $n_{2}$ are fatigue material parameters obtained from the experiments using the least square technique for fitting the experimental data. $\Delta K=K_{\max }-K_{\min }$ is the stress intensity factor range in the loading cycle, $K_{\mathrm{IC}}$ is the critical stress intensity factor or fracture toughness, $K_{\mathrm{IC}}=\Delta K_{\mathrm{C}} /(1-R)$, where $\Delta K_{\mathrm{C}}$ stands for critical stress intensity factor range. Values of the coefficient $C$ and exponents $m, n_{1}$ and $n_{2}$, along with stress intensity factor range values at the fatigue threshold, $\Delta K_{\mathrm{th}}$, are given in Table 4. The results for the fracture toughness, $K_{\mathrm{IC}}$, are in good agreement with those reported in the literature [15-17]. In Refs [15-17] the critical stress intensity factor value, $K_{\mathrm{IC}}$, for nodular cast iron a

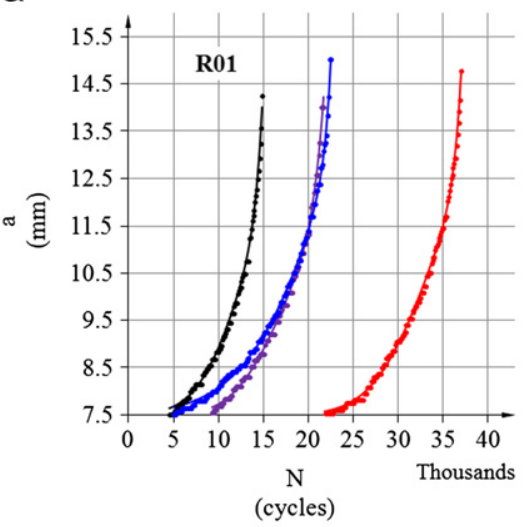

b

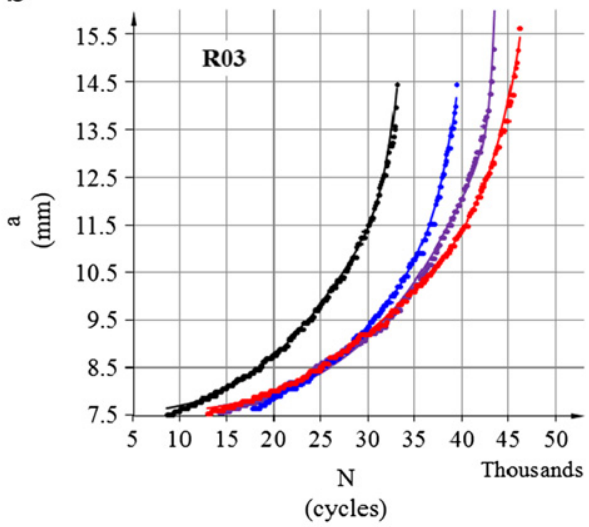

C

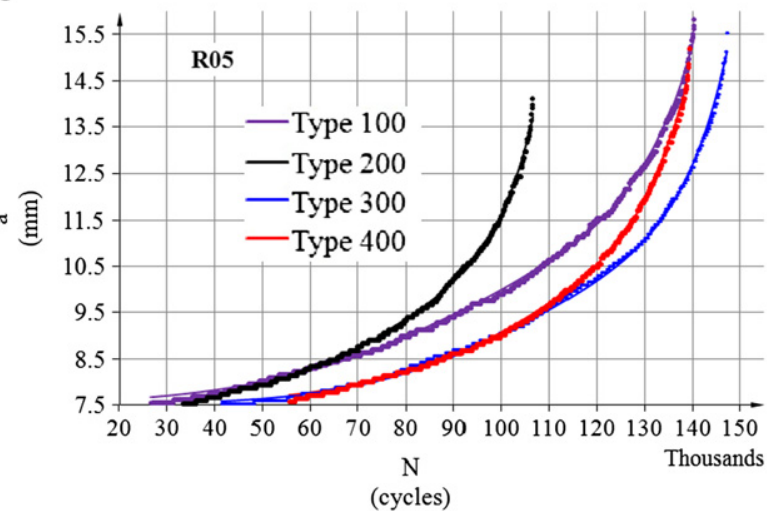

Fig. 12. Number of cycles vs. crack length for: (a) $R=0.1$; (b) $R=0.3$ and (c) $R=0.5$ load ratio. 
a

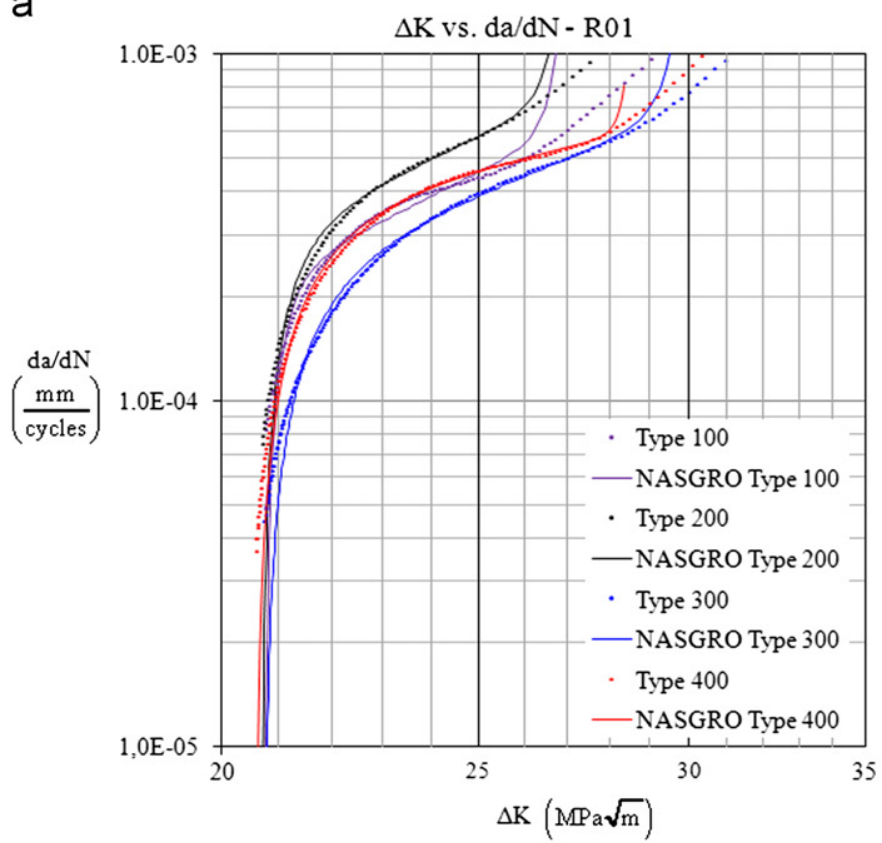

b

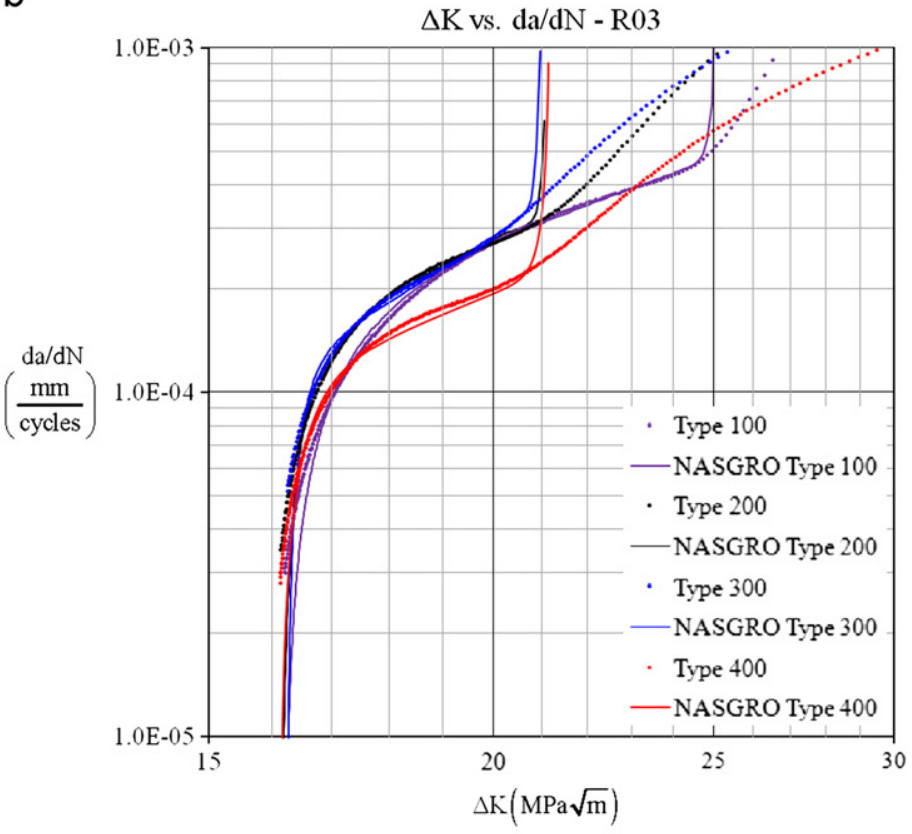

C

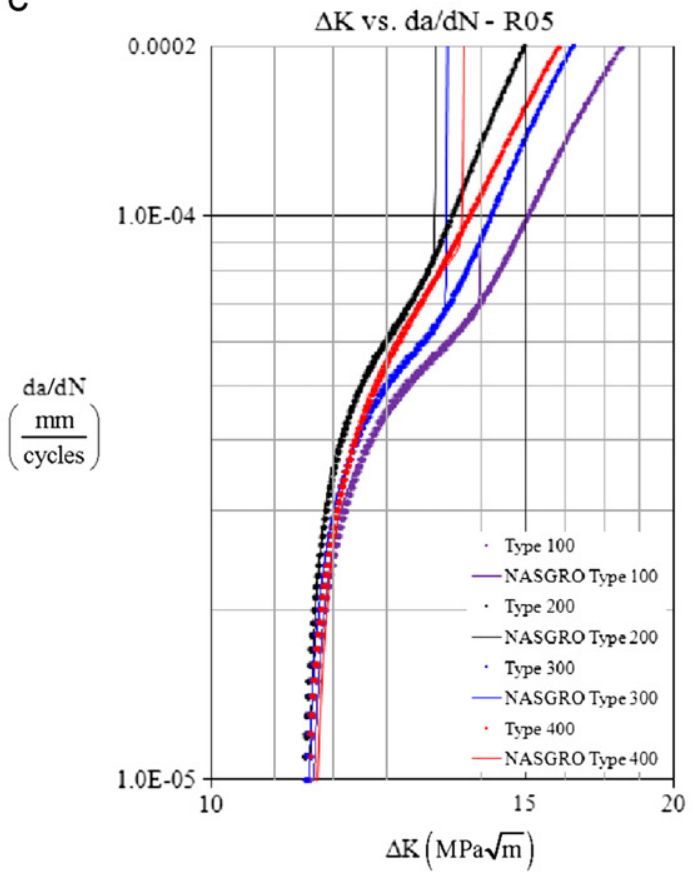

Fig. 13. Diagram $\mathrm{d} a / \mathrm{d} N-\Delta K$ for: (a) $R=0.1$; (b) $R=0.3$ and (c) $R=0.5$ load ratio.

EN-GJS-400-18-LT is between 32 and $40 \mathrm{MPa} \sqrt{\mathrm{m}}$, while the $K_{\mathrm{IC}}$ values presented in Table 4 are between 31.8 and 36.3. In Fig. 13 the NASGRO fits are shown and plotted with coloured line against the experimental data presented with coloured dots with same colour for the same type of material. It is evident that the NASGRO equation fits the lower $\Delta K$ region quite well, but it deviates slightly for large $\Delta K$, especially in the third region for unstable crack growth. This kind of unstable crack growth behaviour has been confirmed in the literature covering experimental data for the LCF crack growth [30].

As already mentioned in the Introduction, the investigations made by the researchers at the Technical University, Bergacademy Freiberg [14-16] show that increasing size of the graphite nodules with high shape factor (CSF $\approx 0.8$ ) leads to higher $\Delta K_{\mathrm{th}}$, lower $\mathrm{d} a / \mathrm{d} N$ and higher $\Delta K_{\mathrm{C}}$. Unlike that, the results presented in this paper (Fig. 13) show that nodular cast iron (type 200) with bigger, more irregular in shape, nodules $(\mathrm{CSF} \approx 0.57)$ has higher crack growth rate and smaller value of critical stress intensity factor $\Delta K_{\mathrm{C}}$ compared to other types of nodular cast iron with larger number of, smaller and more regular in shape, nodules $(\mathrm{CSF} \approx 0.7)$. This applies to all three stages of fatigue crack growth curves. Besides that, it is shown that for the analyzed types of nodular cast iron there is no significant difference between the threshold stress intensity factor range, $\Delta K_{\text {th }}$ which is evident from Table 4 . Therefore, the material type 200 with approximately $70 \%$ larger nodules and $20 \%$ smaller shape factor shows worse fatigue 
Table 4

Fatigue material parameters of nodular cast iron.

\begin{tabular}{|c|c|c|c|c|c|c|c|}
\hline Material type & $R$ & $C$ & $m$ & $n_{1}$ & $n_{2}$ & $\Delta K_{\mathrm{th}}\left(\mathrm{MPa} \mathrm{m} \mathrm{m}^{1 / 2}\right)$ & $K_{\mathrm{IC}}\left(\mathrm{MPa} \mathrm{m} \mathrm{m}^{1 / 2}\right)$ \\
\hline \multirow[t]{3}{*}{100} & 0.1 & $4.608 \mathrm{E}-09$ & 3.86 & 59.81 & 86.50 & 20.8 & \multirow[t]{3}{*}{34,1} \\
\hline & 0.3 & $3.295 \mathrm{E}-07$ & 2.35 & 14.23 & 190.80 & 16.2 & \\
\hline & 0.5 & $1.255 \mathrm{E}-08$ & 3.24 & 36.17 & 724.60 & 11.5 & \\
\hline \multirow[t]{3}{*}{200} & 0.1 & $1.161 \mathrm{E}-08$ & 3.63 & 37.41 & 77.29 & 20.7 & \multirow[t]{3}{*}{31.8} \\
\hline & 0.3 & $6.492 \mathrm{E}-08$ & 2.91 & 19.96 & 240.90 & 16.0 & \\
\hline & 0.5 & $1.045 \mathrm{E}-09$ & 4.34 & 46.90 & 724.00 & 11.5 & \\
\hline \multirow[t]{3}{*}{300} & 0.1 & 4.719E-08 & 3.03 & 20.70 & 64.71 & 20.8 & \multirow[t]{3}{*}{36.3} \\
\hline & 0.3 & $1.658 \mathrm{E}-09$ & 4.19 & 60.75 & 219.60 & 16.2 & \\
\hline & 0.5 & 7.881E-09 & 3.47 & 33.06 & 819.20 & 11.5 & \\
\hline \multirow[t]{3}{*}{400} & 0.1 & $2.233 \mathrm{E}-06$ & 1.80 & 17.97 & 144.60 & 20.6 & \multirow[t]{3}{*}{35.8} \\
\hline & 0.3 & $9.014 \mathrm{E}-08$ & 2.67 & 34.60 & 118.60 & 16.1 & \\
\hline & 0.5 & $1.143 \mathrm{E}-08$ & 3.40 & 22.39 & 485.20 & 11.6 & \\
\hline
\end{tabular}

behaviour than the other three types of materials. These results are consistent with those reported by Mottitscka et al. [17]. As described in the Introduction, in Ref. [17], it is shown that the nodular cast iron with approximately 70\% larger nodules and 30\% smaller shape factor has similar fatigue behaviour as that with finer graphite microstructure.

Furthermore, the fracture toughness tests are performed in accordance with ASTM standard E1820. The unloading compliance technique is used to determine $J$-integral resistance curves $(J-\Delta a)$ from the SEB specimens (Fig. 2b). The crack mouth opening displacement (CMOD) is measured with a clip gauge mounted on knife edges attached to the specimen surface as shown in Fig. 10b. Before fracture toughness tests, a precracking stage was performed until a total crack length (machined notch and fatigue crack) was around $10 \mathrm{~mm}$ (Fig. 2b). Precracking is performed under load control (sinusoidal cycles at $10 \mathrm{~Hz}$ frequency). Representative load-crack mouth opening displacement and $J$-integral resistance curves from unloading compliance tests are shown in Fig. 14. Here, the lines needed for the evaluation of critical $J$ values at $0.2 \mathrm{~mm}$ crack propagation $\left(J_{0.2}\right)$ are added to the $J-\Delta a$ curves. The $J_{0.2}$ values given in Table 3 are in the range of $74-86 \mathrm{~kJ} / \mathrm{m}^{2}$. The present results for $J_{0.2}$ agree well with those obtained by Pusch [16] $\left(J_{0.2}=74 \mathrm{~kJ} / \mathrm{m}^{2}\right)$. The maximal values of $J_{0.2}$ are obtained for material types 300 and 400 produced by the tundish and inmould techniques. Somewhat lower $J_{0.2}$ values are obtained for material type 100 , while material type 200 with large irregularly shaped graphite nodules, shows again the least crack resistance. Considering the proportion of pearlitic phase, it can be seen that fracture toughness of the material type 100 is lower than the type 300 and 400 ones. Thus, the results show that increasing pearlite proportion decreases $J_{0.2}$. These results are in agreement with previous investigations on the influence of the relative proportions of ferrite and pearlite on $J_{0.2}$ of ferritic spheroidal graphite cast iron [31].

\section{Conclusion}

The monotonic tensile, cyclic deformation and fatigue behaviour of the ductile nodular cast iron EN-GJS-400-18-LT has been studied experimentally. Four types of the cast iron produced by different technologies are considered. The influence of the graphite morphology (size, shape and distribution) as well as microstructure phase (ferritic and pearlitic) on the mechanical behaviour has been investigated in the general context of elastoplastic and fatigue behaviours.

In the first part of the experimental investigation, monotonic, cyclic, symmetrical and unsymmetrical strain controlled tests are performed on the smooth cylindrical specimens. Monotonic tension tests results show that nodular cast iron 100 with the highest content of pearlite has higher yield and ultimate tensile strength than other three types of materials. Material type 200, produced by the flotret process, with the smallest pearlite fraction, has the weakest mechanical properties. From the uniaxial strain controlled cyclic tests results, it is concluded that even if materials are produced with different technologies they have similar behaviour considering cyclic hardening. The main reason lies in the fact that the cyclic elastoplastic behaviour of all four types of nodular cast iron in major part depends on ferritic matrix microstructure which provides large ductility of that material and which share is almost equal in all four types of nodular cast iron. Further, they have a similar hardening rate, but the difference exists in achieving maximum stress in first and all subsequent half-cycles as well as in achieving the first yielding point. Considering symmetrical and unsymmetrical strain controlled cyclic tests there is a general conclusion that the material type 200 has the worst characteristics, while the material type 400 produced by the inmould process has the best characteristics and most regular behaviour. Besides, the results showed that mean strain has no significant effect on the cyclic hardening behaviour of the investigated materials.

Furthermore, the crack initiation and propagation tests for different loading ratios are carried out on the CT and SEB specimens. For the detection and measurement of fatigue crack growth a new optical method has been developed in the present work. Using ARAMIS software for digital image correlation and the scripts written in the Python language, the determination of the crack tip is completely automated as a real time process. The experimental results indicate that the size, shape and distribution of the graphite nodules as well as the microstructure phase (ferritic and pearlitic) have significant influence on the material fatigue behaviour. It is found that the material type 200 with approximately $70 \%$ larger nodules and $20 \%$ smaller shape factor has worse fatigue behaviour than the other three types of materials with larger number of, smaller and more regular in shape, nodules. The material type 400 produced by the inmould process and in some cases of loading ratios, material type 300 , produced by the tundish technology, shows the best results. Accordingly, increasing irregularly shaped graphite particle size leads to higher crack growth rate and smaller value of critical stress intensity factor $\Delta K_{\mathrm{C}}$. Besides, the results show that for the analyzed types of nodular cast iron there is no significant difference between the threshold stress intensity factor range, $\Delta K_{\text {th }}$.

Finally, considering the number, shape and size of the graphite nodules, as well as the proportion of pearlitic phase, one can conclude that larger irregularly shaped nodules regardless the proportion of the pearlitic phase has unfavourable influence on 
a

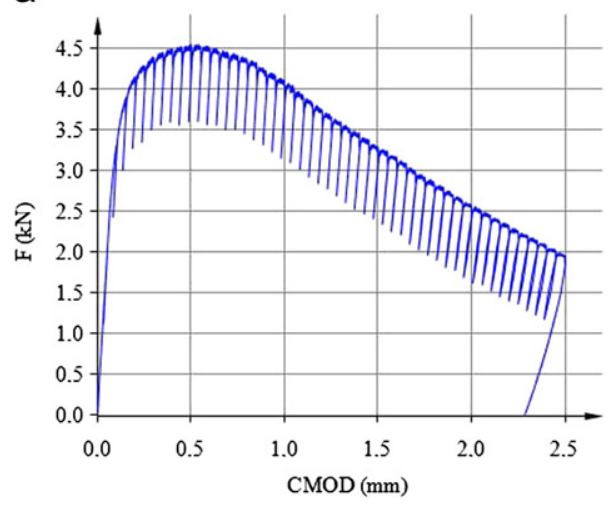

b

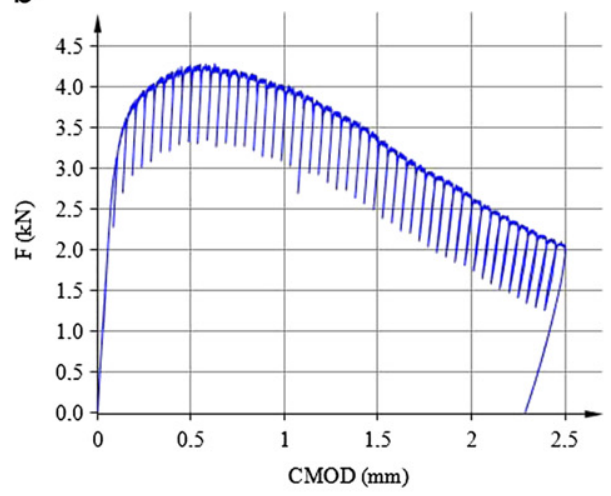

C

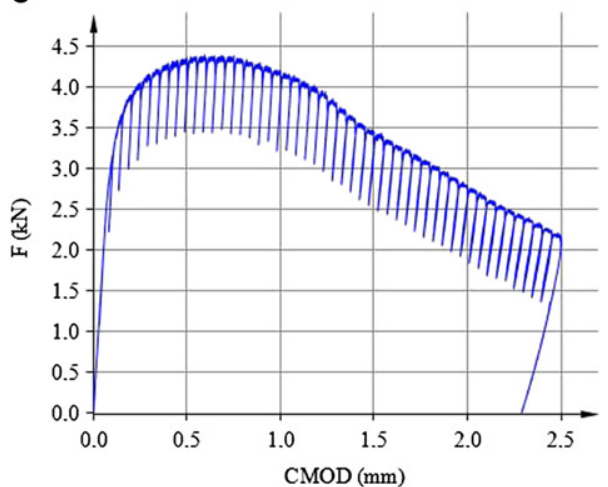

d

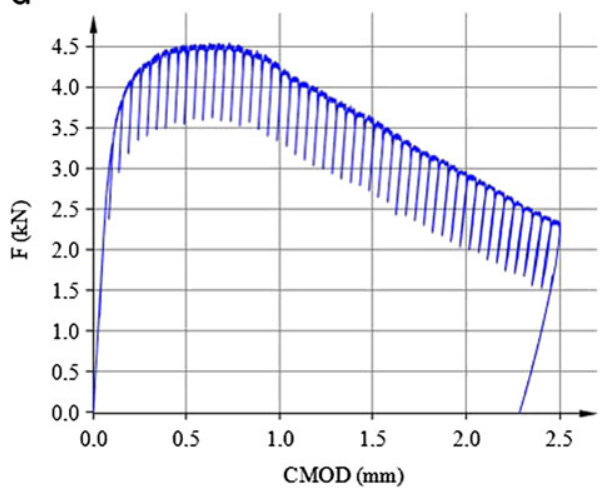

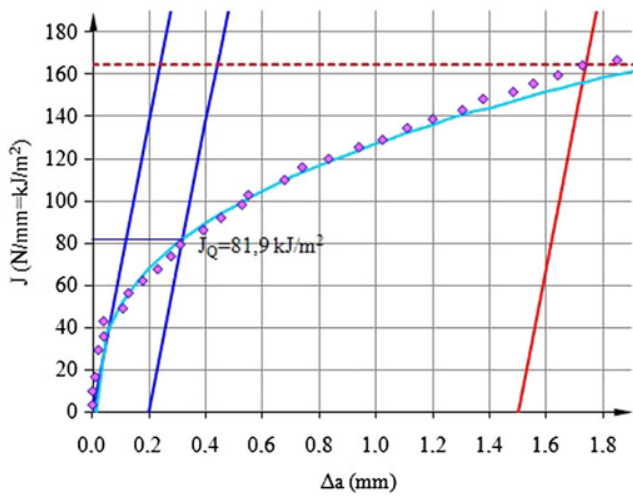
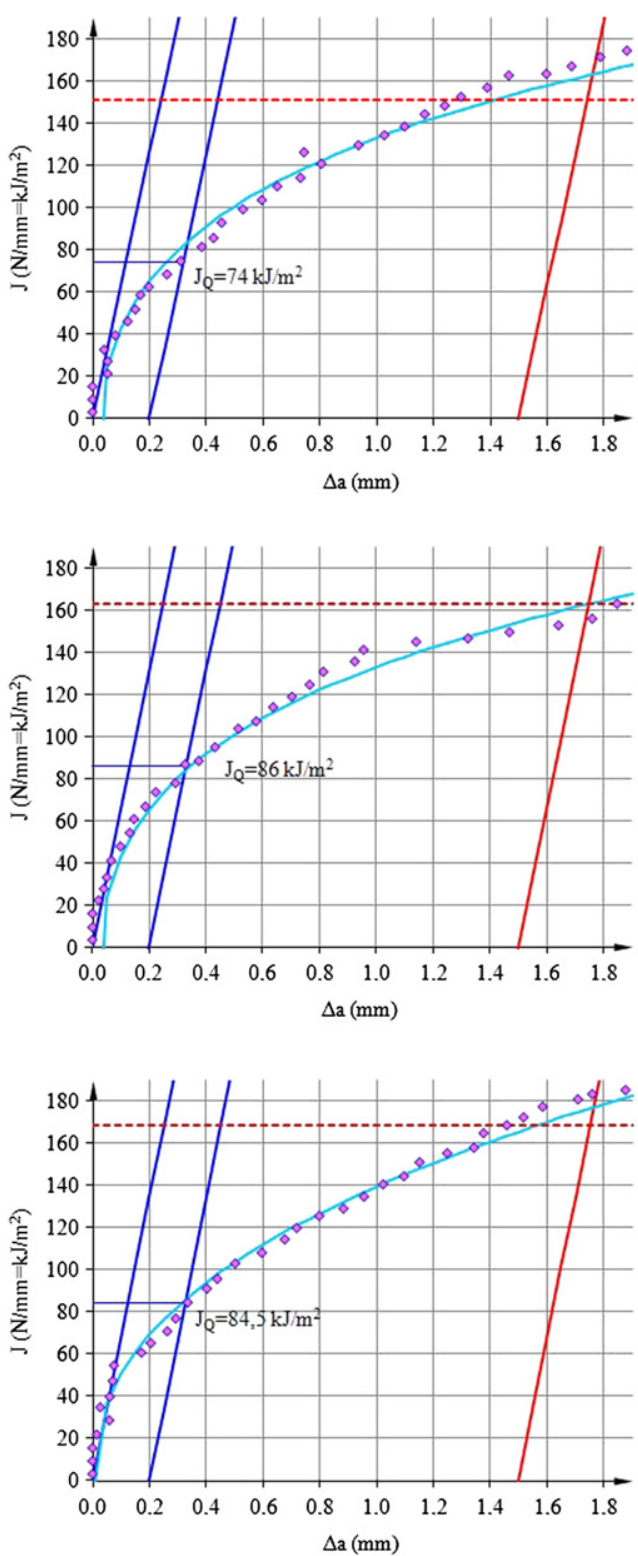

Fig. 14. Load vs. crack mouth opening displacement and $J-R$ curves for: (a) type 100; (b) type 200; (c) type 300 and (d) type 400 of the nodular cast iron.

the fatigue life of cracked components. Also, the beneficial influence of the regular shape of graphite nodules is noticed. Smaller, regular nodules, regardless the amount of pearlitic phase, can endure significantly longer than the specimens with larger, less regular nodules and smaller proportion of pearlitic phase. Pearlitic phase is not so influential if its proportion does not exceed $10 \%$. 


\section{Acknowledgement}

The investigations described in this paper are part of the project "Development of Fatigue Analysis Procedure for Wind Turbine Components" (TP-09/0120-55) supported by the Croatian Institute of Technology and KONČAR-Electrical Engineering Institute, Inc.

\section{References}

[1] P. Clement, J.P. Angeli, A. Pineau, Fatigue Fract. Eng. Mater. Struct. 7 (1984) 251-265.

[2] C. Guillemer-Neel, V. Bobet, M. Clave, Mater. Sci. Eng. A 272 (1999) 431-442.

[3] B. Stokes, N. Gao, P.A.S. Reed, Mater. Sci. Eng. A 445-446 (2007) 374-385.

[4] P. Minnebo, K.-F. Nilsson, D. Blagoeva, J. Mater. Eng. Perfor. 16 (2007) 35-45.

[5] H.Q. Xuea, E. Bayraktarb, C. Bathias, J. Mater, Process. Technol. 202 (2008) 216-223.

[6] J.R. Davis (Ed.), ASM Specialty Handbook-Cast Irons, ASM International, Metals Park, OH, 1996.

[7] N. Costa, N. Machado, F.S. Silva, J. Mater. Eng. Perfor 17 (2007) 352-362.

[8] F. Iacoviello, O. Di Bartolomeo, V. Di Cocco, V. Piacente, Mater. Sci. Eng. A 478 (2008) 181-186.

[9] N. Costa, N. Machado, F.S. Silva, Int. J. Fatigue 32 (2010) 988-995.

[10] M. Shirani, G. Härkegård, N. Morin, Proc. Eng. 2 (2010) 1125-1130.

[11] H.R. Zambrano, G. Härkegård, Proc. Eng. 2 (2010) 1531-1537.

[12] M. Shirani, G. Härkegård, Eng. Fail. Anal. 18 (2011) 12-24.
[13] B. Šamec, I. Potrč, M. Šraml, Eng. Fail. Anal. 18 (2011) 1424-1434.

[14] H. Stroppe, G. Pusch, A. Ludwig, Giessereiforschung 54 (2002) 115-120.

[15] P. Hübner, H. Schlosser, G. Pusch, H. Biermann, Int. J. Fatigue 29 (2007) 1788-1796.

[16] G. Pusch, Bruchmechanische Kennwerte von Gusseisen. Konstruieren + gießen 33 (2008) 2-34.

[17] T. Mottitschka, G. Pusch, H. Biermann, L. Zybell, M. Kuna, Proc. Eng. 2 (2010) 1557-1567.

[18] J.L. Chaboche, Int. J. Plasticity 2 (1986) 149-188

[19] S. Pommier, Int. J. Fatigue 25 (2003) 983-997.

[20] J. Sorić, Z. Tonković, W.B. Krätzig, Comput. Struct. 78 (2000) 161-168.

[21] Z. Tonković, J. Sorić, I. Skozrit, Comput. Model. Eng. Sci. (CMES) 26 (2008) 75-90.

[22] P. Čanžar, Z. Tonković, A. Bakić, J. Kodvanj, Key Eng. Mater. 488-489 (2011) 182-185.

[23] J. Eufinger, A. Heinrietz, T. Bruder, H. Hanselka, Forni di Sopra (UD), Italy, 2011, 34-41.

[24] ASTM Standard E1820-01, Standard Test Method for Measurement of Fracture, 2002.

[25] Y. Ochi, K. Masaki, T. Matsumura, T. Sekino, Int. J. Fatigue 23 (2001) 441-448.

[26] L. Bubenko, R. Konečná, G. Nicoletto, Mater. Eng. 16 (2009) 13-18.

[27]〈www.gom.com 〉.

[28] N. Gubeljak, M.D. Chapetti, J. Predan, J.D. Landes, Eng. Fract. Mech. 78 (2011) 2286-2297.

[29] N. Shiramine, K. Shimizu, T. Narita, T. Noguchi, Bulletin of the Faculty of Engineering (1990), No. 150.

[30] D. J. Klingerman, K. H. Frank, J. W. Fisher, Fritz Engineering Laboratory Report, 1971, 358.31.

[31] J.P. Monchoux, C. Verdu, R. Fougeres, Script. Mater. 42 (2000) 1047-1052. 